\title{
Journaling: A quasi-experimental study of student nurses' reflective learning ability
}

\author{
LP Fakude, (M.Sc), Department of Nursing Education, University of the Witwatersrand \\ JC Bruce, (M.Sc), Department of Nursing Education, University of the Witwatersrand
}

\section{Abstract}

The use of journaling or journal writing in clinical education is one of the strategies used to develop critical thinking. Reflective journal writing, as it is commonly known, can nurture many qualities of a critical thinker and promote thoughtful nursing practice. Using a quasi-experimental design in this study, reflective journaling was introduced to a sample of first year Bridging Course student nurses at a Private Nursing Education Institution, to assess its effectiveness in reflective learning.

The study design enabled comparisons between two groups: one group of students assigned to do journaling (experimental group) and another group of students (control group) who did not journal. The students in the experimental group were given a period of eight weeks to joumal their clinical experiences. At the end of this period, both groups were given an exercise, based on a clinical situation, to analyse reflectively and a comparison made on their performance. Descriptive statistics were used to analyse data and Fisher's Exact Test was used to determine the significance of differences observed within and between groups. The results showed that students in the experimental group performed better in exploring alternatives of action $(p<0.10)$ and formulating responses in similar future situations $(p<0.05)$ during the process of reflection. There was no significant difference between the groups' scores with regard to their ability to describe the clinical experience, to explore their related feelings, to evaluate the experience and to interpret/create meaning for themselves. Recommendations are made for continued student support and guidance during clinical education if reflection is considered to enhance reflective, thoughtful nursing practice.

\section{Introduction}

Reflection, as a way of thinking, has been an activity performed by many individuals in their daily lives. Reflection largely relies on the recall of events. In this instance, it refers to the usual mulling over an event or experience. Reflection has been widely used as a teaching strategy through which nurses could develop their practice. This entails recalling the experience, analysing and evaluating the experience; it involves a conscious analysis of the event. Several authors on reflection have referred to the works of Donald Schon $(1983,1987,1991)$ who has written extensively about the importance of reflection and has described ways in which educators could facilitate reflection in practice.

Proponents like Schon (1991) suggest that reflection can be taught and learnt. Several methods can be used to teach and improve the process of reflection. The most commonly advocated methods being writing or documenting one's experiences in a reflective diary (Schon, 1991) or in a journal (Atkins and Murphy, 1993). This would enable nurses to make more explicit the knowledge underpinning their actions. Reflective journals have also been widely reported as an effective strategy to assist students to reflect upon learning experiences in clinical areas (Palmer, Burns and Bulman, 1994; Davies, 1995; Baker, 1996; Fonteyn and Cahill, 1998). The literature review that follows includes the meaning and importance of reflection, the types of reflection, and reflective journaling as an important strategy to develop reflective learning.

\section{Literature review}

Reflection is not a new concept. As early as 1933, Dewey (in Palmer et al., 1994:66) was the first educationist who wrote about reflection on experience and defined it as "looking back on what has been achieved to obtain meaning in order to intelligently deal with further experience" (Klopper, 2000:33). Boyd and Fales (1983) suggest that reflective learning is the process of internally examining and exploring an issue of concern, triggered by an experience, which creates and clarifies meaning in terms of self, and which results in a changed conceptual perspective. This is similar to the explanation by Boud and Walker (1991), who consider reflection as intellectual and effective activities that individuals engage in to explore their experiences in order to lead to new understandings and appreciations. Reflection can therefore be seen as involving the self and a changed conceptual perspective or new understanding.

The importance of reflection is reported in various studies (Patterson, 1994; Palmer, et al., 1994; Wong, Kember, Chung and Yan, 1995; Wellard and Bethune, 1996; Wong, Loke, Wong, Tse, Kan and Kember, 1997; Fonteyn and Cahill, 1998). Retlection can foster deep, holistic learning in students, develop critical thinking and promote thoughtful nursing practice. In clini- 
cal education reflection enables nursing students to relate to aspects of their experiences that most profoundly speak to them at that moment. Tapping into the central concerns creates the greatest potential for professional growth (Baker, 1996:22). In relation to critical thinking, which has been described as a developmental process no different from the growth developmental process, such skills should be nurtured from early on in the professional lives of students. Critical thinking also includes thinking in relation to feelings, values and beliefs; it is a way of life. It involves "rationally deciding what to do or believe" (Norris, 1990). It has also been interpreted as "the extension of logic to the rational examination of controversial social, ethical, political, economic, and religious issues, such as abortion, euthanasia and terrorism" (Bandman and Bandman, 1988:2). Developing critical thinking through reflection is viewed as important to promote thoughtful nursing practice and to prepare nurses as caring, empathetic individuals (Irvin, 1996:109). Reflection is important for holistic nursing education, which prepares students for efficient moral practice as they are increasingly confronted with ethical dilemmas during their nursing practice. Teaching in a reflective environment that stimulates students to express their opinions and where they are encouraged to draw from their own experiences can achieve this. Hence encouraging students to write reflectively could improve their critical thinking skills, which are the skills necessary for ethical decision-making.

Three types of reflection can be identified: reflection-in-action, reflection-on-action and reflection-with. Reflection-in-action involves the learners challenging assumptions about their work, critically examining their present-time actions, and testing alternatives that reshape what they are doing while they are doing it (Carkhuff, 1996:212). While reflecting-in-action, the individual can draw upon knowledge and experience in order to make professional judgements/decisions during practice. Reflection-on-action is a process through which learners look back on an action or event, critically analysing the event/action and evaluating it, leading to a new perspective for future reference (Schon, 1991; Atkins and Murphy, 1993). Reflectionon-action can help an individual to make sense of the experience and as such could result in learning (Mashaba and Brink, 1994; Palmer, et al., 1994; Carkhuff, 1996; Andrew, 1996). Reflection-with is done through dialogue, discourse and narratives and focuses on the development of thinking skills. The focus of this study was on "reflection-on-action".

With reference to reflective strategies, dialogue journals and journaling have been reported in the literature as effective in assisting students to reflect on their learning experiences in the clinical area (Fonteyn and Cahill, 1998). Journaling is said to enable more objective reflection of one's experiences in that it can assist the writer to distance himself/herself from the situation and to differentiate between what has happened and what they think has happened (Patterson, 1994; Palmer, et al., 1994; Wong, et al., 1995). Because reflective ability is necessary for practitioners to effect meaningful development and change in nursing practice, Patterson (1994) is of the opinion that it is worthwhile for nurse educators to continue to grapple with alternative solutions and preventative measures for the difficulties, which may arise in the use of reflective journals.

\section{Statement of the problem}

Authors generally agree that reflective journaling could be uti- lised to improve critical thinking skills, and hence reflective learning in student nurses. The development of these skilis is an essential need since professional nurses are increasingly required to make independent decisions regarding patient management. Nurse educators are exploring various ways to meet this need; the use of reflective journaling reputed to be a useful strategy during clinical education. As a clinical instructor at the time, the researcher deemed it necessary to assess the effectiveness of journaling as a strategy to help students reflect on their clinical learning experiences.

\section{Purpose and objectives of the study}

The purpose of the study was to investigate the use of journaling as a strategy to reflect on clinical experiences by two groups of first year Bridging Course student nurses in a Private Nursing Education Institution. The objectives were to: - $\quad$ assess the ability of student nurses to write reflective journals

- $\quad$ evaluate the effectiveness of journaling as a strategy to promote reflective learning in the experimental group

- compare the reflective learning ability of students who were exposed to journaling (experimental group) to students who were not exposed to journaling (control group).

\section{Definitions}

Clinical experience: The exposure of student nurses to situations where they encounter patients or clients.

Journals: A notebook in which the student records experiences encountered. In this study journals were pocket notebooks size A6.

Journaling: The act of writing in the notebook/journal.

Reflection: The act of internally examining and analysing a clinical experience in order to lead to a new understanding or a new perspective of the situation. Reflection is integral to reflective journaling and reflective learning.

Reflective journaling: The act of writing the experiences reflectively i.e. recalling, reviewing and analysing an event/experience.

Reflective learning: Occurs, upon reflection, when an individual acts on a feeling induced by a clinical experience, recaptures the experience, and makes inferences, generalisations and evaluations. In this study reflective learning involved the use of the six steps in Gibbs' Reflective Cycle ( Palmer, et al., 1994:66).

\section{Research methodology}

A quasi-experimental design was used, which involved two groups of students: one group assigned to write reflective journals (experimental group) and another group of students (control group) who did not journal. Like true experiments, quasiexperiments involve the manipulation of an independent variable (Polit and Hungler, 1993:136), which in this study was achieved by the introduction of journaling to the experimental 


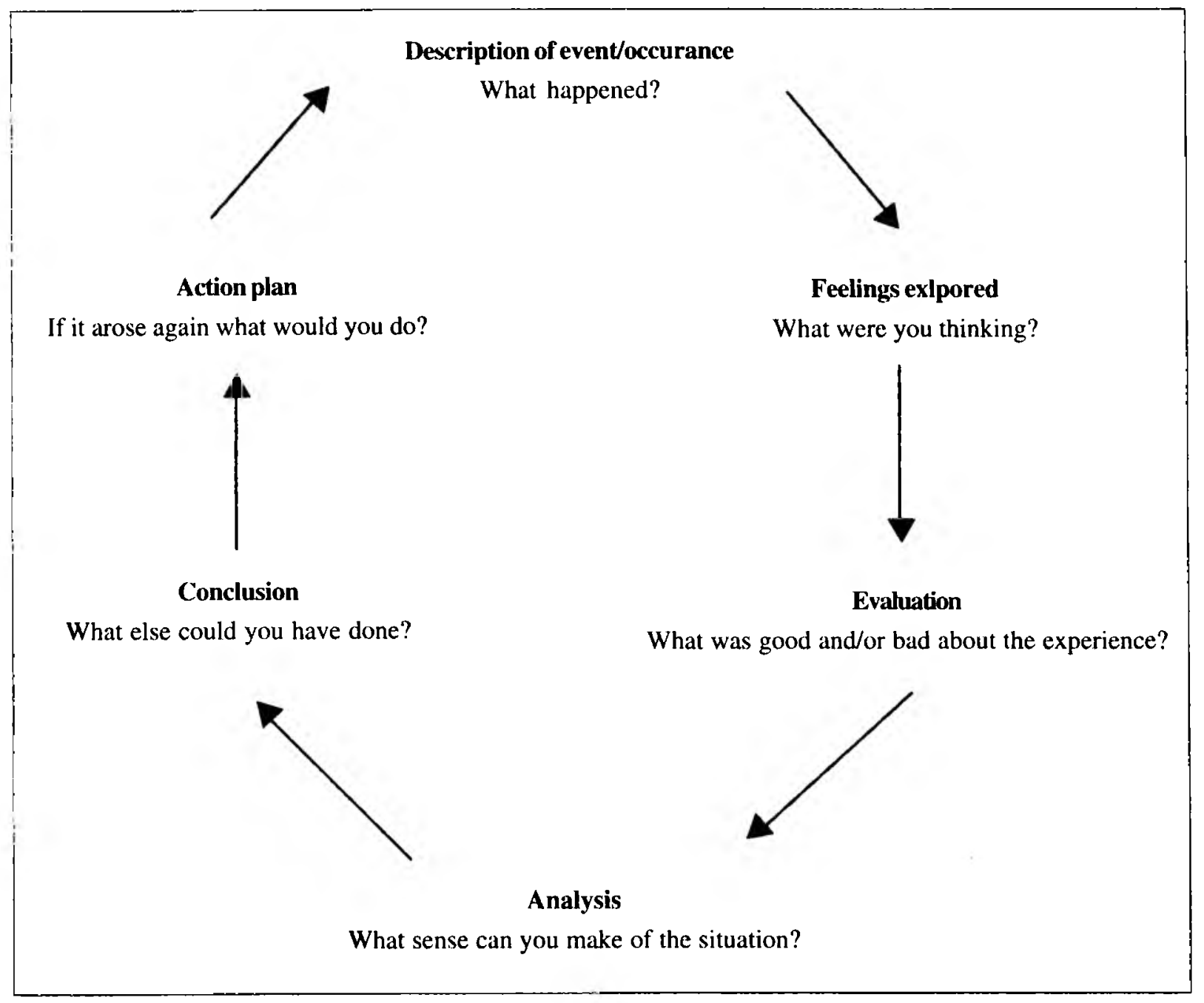

group. Furthermore, a quasi-experimental design is feasible in the clinical situation where there is a potential for ethical or practical barriers (Behi and Nolan, 1996:756), hence its selection for this study. Unlike a true experiment, the two groups were not randomly chosen, neither were the participants randomly assigned to their groups.

\section{Population and sample}

The target population consisted of all the first year students $(\mathrm{N}=53)$ registered for the Bridging Course at a Private Nursing Education Institution. These students attended the course at two separate campuses, i.e. Johannesburg campus (26 students) and Pretoria campus (27 students). The entire population was proposed for inclusion in the study.

The final study sample consisted of all those students who agreed to participate and gave written consent $(n=43)$. Twenty out of twenty-six students at the Johannesburg campus signed consent and twenty-three out of twenty-seven students at the Pretoria campus signed consent.

\section{Constituting the groups}

A non-randomized sample was selected for the two groups. Students at the Johannesburg campus constituted the experimental group $(n=20)$. These students were issued with journals and were exposed to the activity of journaling.
Students at the Pretoria campus constituted the control group $(n=23)$. This separation was to avoid the possibility of crosscontamination between the two groups, which was likely to have occurred had the groups been at the same campus. The students in the control group would not journal during the data collection period and would only be exposed to the activity of journaling at the end of the study. The groups were nonequivalent although they had similar characteristics.

\section{Ethical considerations}

Permission and ethical clearance was obtained from the university's Postgraduate Committee and the Committee for Research on Human Subjects. Permission was requested and obtained from the Head of the Nursing Education Institution.

Each student was provided with an information sheet explaining what the study involved and what their role, as participants would entail. The participants were informed that any information obtained would be used for the purposes of the study only, and that their names would not be disclosed. Participants were given an opportunity to withdraw from the study at any time without prejudice. Those students who agreed to participate were then requested to sign the consent form.

The researcher was available for consultation by the students throughout the duration of the study. This was mainly for the 


\section{Data collection}

Students in the experimental group were required to write anecdotes, in their journals, of their experiences in their respective clinical areas over a period of eight weeks. The participants were to reflect on one experience per week during the clinical placement period and to analyse each experience using the guidelines provided. Palmer et al. (1994:39) find it useful to refer to Gibbs's Reflective Cycle (Figure 1) to help students to reflect. Exploration of the cycle enables the students to identify where they are in terms of their ability to reflect and on the part of the tutor, reduces the risk of assumptions or misinterpretation. Gibbs's Reflective Cycle (Palmer, et al., 1994) was chosen as a framework to formulate guidelines to assist the participants in reflective journaling. The cycle involved the students answering six questions about a significant clinical experience:

- What happened?

- What were my feelings and thoughts?

- What was good and/or bad about the experience?

- What is my personal interpretation of the situation?

- What other ways are there to respond to the event?

- What have I learnt from this situation? If it arose again, what would I do?

The researcher's role was that of resource person and also to play a supportive role to encourage students to continue with the exercise despite perceived problems or barriers.

After the eight-week period of journaling, students in both the experimental group and the control group, were provided with a paper clinical exercise to analyse reflectively. The purpose of the exercise was firstly, to collect data in relation to the effectiveness of journaling to promote reflective learning in the experimental group and secondly, to collect data to compare the performance of the experimental and control groups in reflective learning.

The students in the control group were introduced to the journaling activity only after they had completed analysing the clinical exercise. They too, were provided with guidelines for keeping a reflective journal to assist them through the reflective journaling process. Their journal entries were not evaluated as part of this study.

\section{Issues of validity}

The use of journals and journaling for data collection was validated by recent literature and research studies. Content validity of the marking tool was based on Gibbs's Reflective Cycle (Palmer, et al., 1994) followed by peer review.

\section{Data analysis}

Data analysis involved analysing the jour- nal entries of students in the experimental group to assess their ability to journal and to compare their performance in journaling to their performance in the clinical exercise (withingroup comparison). The performance of the experimental group and the control group in the clinical exercise was also compared (between-group comparison). Fisher's Exact Test was used to determine whether observed differences were significant. The level of significance was set at .05 .

\section{Analysis of Journal Entries (Experimental Group)}

Using a tool with assessment criteria categorised according to the six steps in Gibbs's Reflective Cycle (Palmer et al., 1994) the journal entries of the experimental group were marked to assess their journaling and reflective learning abilities. The number of journal entries ranged between one and four per student. A total of 68 journal entries were marked according to whether entries were "correct" or "incorrect". A score was calculated for each individual participant. A score of $\$ 50 \%$ was regarded as an indicator of the students' ability to journal. The proportion of correct responses for each of the six categories was calculated (Table 1). With the exception of the last item, "formulating response in similar situations in the future", a high percentage of students scored over $50 \%$ in the remaining reflective abilities.

\section{Within-group comparison (experimental group)}

Students in both groups were required to analyse a paper clinical exercise, reflecting their opinions and feelings about the
Table 2: Within-group comparison (Experimental Group): Journaling vs. Exercise Analysis $(n=20)$

\begin{tabular}{|c|c|c|}
\hline Categories of Items & $\begin{array}{l}\text { Journaling } \\
\text { Proportion }\end{array}$ & $\begin{array}{l}\text { Exercise } \\
\text { correct responses }\end{array}$ \\
\hline $\begin{array}{l}\text { Description of event/exercise } \\
\text { Exploring thoughts and feelings } \\
\text { Evaluation of good and/or bad aspects } \\
\text { Analysis for interpretation/meaning to self } \\
\text { Exploration of alternatives of action } \\
\text { Response in similar situation in future } \\
\text { Average }\end{array}$ & $\begin{array}{l}95 \% \\
91.7 \% \\
85.45 \% \\
83.75 \% \\
62.95 \% \\
45.45 \% \\
77.38 \%\end{array}$ & $\begin{array}{l}100 \% \\
100 \% \\
100 \% \\
85 \% \\
75 \% \\
65 \% \\
87.5 \%\end{array}$ \\
\hline
\end{tabular}


situation. The same tool used to score the journal entries above was used to assess the students' ability to reflect on the exercise. The performance of students in the experimental group was assessed for any differences between journaling and analysis of the exercise with regard to the criteria (Table 2). Although there was an overall improvement of 5\%-20\% in the different reflective learning categories, this improvement in scores was not significant $(p>0.05)$.

\section{Between-group comparison (experimental and control groups)}

A comparison between the experimental group and the control group was made to determine if there was any difference in their ability to reflect on the clinical exercise (Table 3 ). This would give an indication of their reflective learning ability. Since the scores in the first three categories of description of the experience, exploring feelings and evaluating the experience were equal for both groups, comparisons were made with respect to the categories of analysis, exploration of alternatives and response only. The results were as follows:

- There was no significant difference between the groups with regard to their ability to analyse to create meaning for self or interpret $(p=0.431)$

- There was no significant difference, at the .05 level of significance, between the groups with regard to their ability to explore alternatives $(p=0.065)$. At a significance level of 0.1 however, the difference would be significant $(\mathrm{p}<0.1)$

- The ability of the experimental group to outline a response in future situations was significantly better than the control group $(p=0.047)$

\section{Discussion of results}

After marking the journal entries of the students in the experimental group the highest scores were obtained in "description of the event" and the lowest in "response in future similar situations". A high proportion of students could describe the clinical events and reflect on or explore their thoughts and feelings very well (95\% and $91.7 \%$ respectively). More than $60 \%$ of the students could explore alternative actions but only $45,45 \%$ were able to formulate new responses in similar situations in the future. These scores indicate that students had no difficulty in recalling the events in order to describe the experience but had increasing difficulty with the higher levels of reflection. Brown and Gillis (1999) are of the opinion that the development of higher-level reflective activities such as these requires expanded discussions in groups where students could re-examine their viewpoints and receive immediate feedback. The absence of group discussion, as was the case in this study, may therefore be a factor to be considered in drawing any conclusions.

The performance of students in the experimental group in reflective journaling was compared to how they performed in the clinical exercise. Overall, there was a $10,12 \%$ improvement on the scores obtained when analysing the clinical exercise. This improvement however, was not statistically significant $(\mathrm{p}>$ 0.05 ). It may be concluded therefore that the journaling exercise is not related to the improvement in reflective learning.

The performance of the control group in the analysis of the exercise was assessed and compared to the results of the experimental group. The performance of the participants in both groups was equal regarding the first three criteria. A comparison between the two groups showed a difference in the proportion of correct responses obtained by the two groups in the last three categories i.e. analysis to enable interpretation/meaning to self, exploration of alternatives of action and response in similar situations in the future. Students in the control group performed better than those in experimental group with regard to analysing the experience to create meaning for themselves. This difference however, was not significant $(\mathrm{p}>0.05)$. The students in both groups obtained the lowest scores in the last two criteria, i.e. exploration of alternatives of action and response regarding similar situations in future. This means that students in both groups performed poorly in the higher levels of the reflective process. With reference to their ability to formulate a response in similar future situations the experimental group performed significantly better than the control group ( $p$ $<0.05$ ). This level of reflection requires students to view a phenomenon from a different perspective and to translate new knowledge and insights into action. Unless there is evidence of the development of this level of reflection Boud and Walker (1991) caution that professionals may not be able to deal with clinical problems intelligently. It may be concluded that journaling assists students to construct responses to clinical problems, which resemble those they have encountered as part of the learning experience.

\section{Recommendations}

\section{Nursing Education}

Journaling is encouraged as a strategy to enhance reflective learning and critical thinking.

The nurse educator, as facilitator of learning, should incorporate additional techniques to encourage reflection. Poor to average scores in higher level reflective abilities were observed in this study. Expanded group discussion (Brown and Gillis, 1999) as an example of an additional technique is recommended to facilitate the process of outlining future response in similar situations/scenarios. Discussions of ethical dilemmas have to be frequently stimulated and incorporated in ethical decisionmaking relevant to the clinical situations. Apart from enhancing reflective learning, discussions afford students an oppor- 
tunity to debrief as well. The discussions would also create an environment in which the students would re-examine their viewpoints and receive immediate feedback from their colleagues. The role of the nurse educator would be to facilitate the dialogue and encourage participation. It is further recommended that nurse educators reflect with their learners as true participants in the learning process in order to develop the necessary expertise to support students. In this regard the role of the nurse educator is sharing experiences in order to construct meaning (Klopper, 2000:38) and giving expert support (Palmer, et al., 1994:71) when difficulties are encountered.

\section{Research}

It is recommended that further research be conducted on how the process of reflection could be facilitated to achieve higher levels of reflective thinking since the results of this study show deficient ability at this level. The assumption, as documented in journals, that reflective thinking is transferred to practice (i.e. may improve patient care), needs to be explored empirically for any conclusions to be made.

More appropriate evaluation tools should be developed to assess reflective learning and critical thinking ability of students. The assessment of "correct" and "incorrect" responses used in this study was inadequate to discriminate between students' reflective abilities. Authors (Gross, Takazawa and Rose, 1987; Perciful and Nester, 1996; Kim, 1999; Platzer, Blake and Ashford, 2000) concur that critical, reflective thinking is difficult to assess empirically. A more precise, focused approach is needed to assess skills in reflection, as well as patient outcomes, as an indication of the effectiveness of journaling.

\section{Conclusion}

This study was based on the use of journaling as one of the strategies that could be used to improve reflective learning among nursing students. Reflective practice is a valuable tool in nursing education because independent practice demands continuing development and growth on the cognitive and affective domains of learning. Reflective journaling is one of the strategies that could develop learning in these domains and promote mindful, thoughtful nursing practice. As nursing changes to meet new societal demands, the need for improved, innovative ways to respond to these demands sensibly and professionally, will become more pressing. Reflective journaling is not the only answer but it provides the means for professionals to prolong the value of knowledge by adapting and transforming knowledge to meet changing circumstances.

\section{References}

ANDREW, ME 1996: Reflection as infiltration: Learning in the experiential domain. Journal of Advanced Nursing. 24: 391 399.

ATKINS, S. \& MURPHY, K 1993: Reflection: a review of the literature. Journal of Advanced Nursing. 18:1188-1192.

BANDMAN, EL \& BANDMAN, B 1988: Critical Thinking in Nursing. California: Appleton \& Lange.

BAKER, CR 1996: Reflective Learning: A Teaching Strategy for Critical Thinking. Journal of Nursing Education. 35(1): 1922.

BEHI, R \& NOLAN, M 1996 : Quasi-experimental research designs. British Journal of Nursing. 5(17): 1079-1081.

BOUD, D \& WALKER, D 1991: Experiencing and learning: Reflections at work. Deakin University Press: Geelong.

BOYD, EM \& FALES, AW 1983: Reflective learning: Key to learning from experience. Journal of Human Psychology. 23(99): 99-117.

BROWN, SC \& GILLIS, MA 1999: Using Reflective Thinking to Develop Personal Professional Philosophies. Journal of Nursing Education. 38(4): 171-175.

CARKHUFF, MH 1996: Reflective learning: Work Groups as Learning Groups. The Journal of Continuing Education in Nursing, 27(5): 209-214.

DAVIES, E 1995: Reflective Practice: A Focus for Caring. Journal of Nursing Education. 34(4): 167-174.

FONTEYN, ME \& CAHILL, M 1998: The use of clinical logs to improve nursing students' meta-cognition: a pilot study. Journal of Advanced Nursing. 28( 1): 149-154.

GROSS, Y; TAKAZAWA, E \& ROSE, C 1987: Critical thinking and nursing education. Journal of Nursing Education. 26: 317-323.

IRVIN, SM 1996: Creative Teaching Strategies. The Journal of Continuing Education in Nursing. 27(3): 108-1 14.

KIM, HS 1999: Critical reflective inquiry for knowledge development in nursing practice. Journal of Advanced Nursing. 29(5): 1205-1212.

KLOPPER, HC 2000: Nursing Education: A Reflection. Pretoria: Amabhuku Publishers.

MASHABA, TG \& BRINK, HI 1994: Nursing Education. An international perspective. Kenwyn: Juta.

NORRIS, SP 1990: Understanding Educational Evaluation. London: Kogan Page.

PALMER, A; BURNS, S \& BULMAN, C 1994: Reflective Prac- 
tice in Nursing: The Growth of the Professional Practitioner. Oxford: Blackwell Scientific.

PATTERSON, BL 1994: Developing and maintaining reflection in clinical journals. Nurse Education Today. 4:211-220.

PERCIFUL, EG \& NESTER, PA 1996: The Effect of an Innovative Clinical Teaching Method on Nursing Students Knowledge and Critical Thinking Skills. Journal of Nursing Education, 35(1): 23-28.

PLATZER, H; BLAKE, D \& ASHFORD, D 2000: An evaluation of process and outcomes from learning through reflective practice groups on a post-registration nursing course. Journal of Advanced Nursing. 32(9): 425-428.

POLIT, DE.\& HUNGLER, BP 1993: Nursing Research Principles and Methods. 4th ed. Philadelphia: Lippincott.

SCHON, DA 1983: The reflective practitioner: how individuals think in action. New York: Basic Books.

SCHON, DA 1987: Educating the reflective practitioner. San Francisco: Jossey Bass.

SCHON, DA 1991: The Reflective Practitioner. 2nd ed. San Francisco: Jossey Bass.

WELLARD, SJ \& BETHUNE, E 1996: Reflective Journal writing in Nurse Education: Whose interests does it serve? Journal of Advanced Nursing. 24: 1077-1082.

WONG, FKY, KEMBER, D, CHUNG, LY \& YAN, L 1995: Assessing the level of student reflection from reflective journals. Journal of Advanced Nursing. 22: 48-57.

WONG, FKY, LOKE, AY, WONG, M, TSE, H, KAN, E \& KEMBER,D 1997: An action Research Study into the Development of Nurses as Reflective Practitioners. Journal of Nursing Education 36(10): 477-481. 